\title{
Fatores de ameaça à estabilidade nos faxinais do Paraná: caso do Taquari dos Ribeiros*
}

\section{Threat factors to the stability of the "faxinal" areas of the Paraná State: the case of the Taquari dos Ribeiros}

\author{
Olivier François Vilpoux \\ Universidade Católica de Campo Grande - UCDB
}

\begin{abstract}
Resumo: A tradição faxinalense, baseada em atividades agrosilvopastoris e costumes específicos, se encontra ameaçada. Vários fatores têm sido apontados como causa dessa ameaça, como o agronegócio capitalista, a presença de "estrangeiros" ao faxinal e a influência das novas gerações. O objetivo da pesquisa foi avaliar o impacto desses fatores sobre as tradições do faxinal Taquari dos Ribeiros, PR. Para isso, todas as famílias do faxinal foram entrevistadas. A análise não revelou influência significativa de todos esses fatores, entretanto, foi encontrada uma redução da solidariedade. Apesar de existir a prática de troca de implementos entre os produtores de fumo, os princípios de solidariedades encontram-se em queda na maioria da comunidade, independente da idade, o que indica um problema antigo.
\end{abstract}

Palavras-chave: Comunidades tradicionais. Fumo. Agronegócio. Tradições.

\begin{abstract}
The traditions of the "faxinal" areas, which are based on agriculture, pasture and forestry systems and specific customs, are threatened. Several factors have been deemed responsible, such as the capitalist agribusiness, the presence of "foreigners" in the region, and the influence of new generations. The aim of this research was to investigate the role of these factors on the traditions of the Taquari dos Ribeiros "faxinal", in the Paraná State, South of Brazil. In order to do so, all families in the community were interviewed. The analysis revealed that these factors had no significant influence in the above-referred issues. However, it was possible to identify a decrease in solidarity in the region. Despite the practice of exchanging implements among tobacco producers, the principles of solidarity are decreasing in most of the Community, regardless of age, which indicates a deep and old problem.
\end{abstract}

Keywords: Traditional communities. Tobacco. Agribusiness. Traditions.

* Este trabalho é resultado do projeto de pesquisa "Compreendendo geograficidades existenciais de povos e comunidades tradicionais: quilombolas e faxinalenses no Paraná", financiado pela Fundação Araucária, no estado do Paraná e coordenado pela Profa. Dra. Cicilian L. Löwen Sahr (DEGEO-UEPG). 


\section{INTRODUÇÃO}

O Sistema Faxinal é uma forma de organização da agricultura familiar específica da região centro-sul do Paraná, caracterizada pela presença de dois espaços distintos: o criadouro comunitário ou coletivo e as "terras de plantar" (Figura 1). No primeiro residem os moradores da comunidade, onde são criados animais soltos. As "terras de plantar" são destinadas ao cultivo e localizadas ao redor do criadouro comunitário.

Figura 1 - Estrutura típica de um faxinal

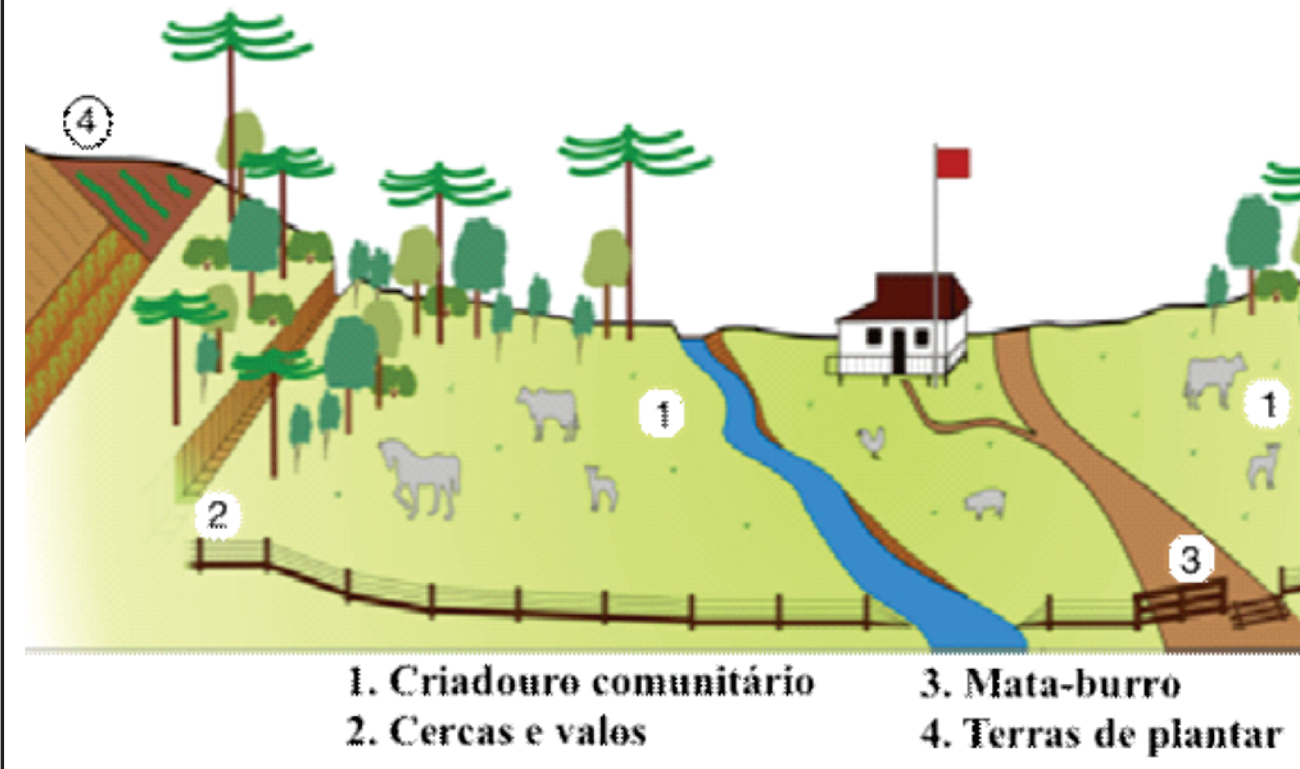

Fonte: Egger (2009)

Este modo de vida foi bastante frequente no Sul do Brasil até os anos sessenta do século XX, mas nos últimos anos, em função da modernização da agricultura, muitos faxinais desapareceram. O estado do Paraná é o único em que ainda existem comunidades deste tipo, localizadas principalmente na região da Floresta com Araucária.

Para Floriani et al. (2009) e Almeida e Souza (2009), as atividades produtivas tradicionais dos faxinais paranaenses, tais como a criação extensiva, o extrativismo e as culturas diversificadas e de subsistência, estão sendo substituídas por monoculturas, principalmente fumo, soja, pinus e criações intensivas. $\mathrm{O}$ crescimento demográfico e o aumento do preço das terras também ameaçam a sobrevivência dos faxinais, assim como a implantação de chácaras por moradores da cidade (TAVARES, 2008 e FLORIANI et al., 2009).

Neiverth e Löwen Sahr (2009) afirmam que o modo de vida tradicional dos faxinais é baseado em atividades agrosilvopastoris regidas por uma organização social comunitária e por tradições e costumes específicos. Os autores citam os trabalhos em grupo (puxirão, ou mutirão), as festas religiosas, a vivência comunitária e a preservação da Floresta com Araucária como característica do modo de vida nos faxinais. 
O sistema faxinal se assemelha a outras formas de organização rural que mantêm um eixo familiar de produção. Entretanto, sua forma de organização ou ordenamento territorial o torna um exemplo singular, com uso coletivo da terra para produção animal e estruturação social. Apesar do uso coletivo da terra, a propriedade continua sendo particular (BARBOSA, 2007).

O primeiro levantamento mais abrangente sobre o número de faxinais no Sul do Brasil data de 1994, da Empresa Paranaense de Assistência Técnica e Extensão Rural (EMATER). Segundo este levantamento, em 1994 o número de faxinais no Paraná chegava a 121. Uma atualização efetuada pelo IAP (Instituto Ambiental do Paraná) demonstra que 44 destes ainda se mantinham dez anos depois. Estes faxinais agregavam cerca de 3.000 famílias, com uma população de aproximadamente 16.000 habitantes (LÖWEN SAHR e CUNHA, 2005).

Os dados de Tavares (2008) para 2007, baseados em levantamento do movimento Articulação Puxirão, indicavam um total de 227 faxinais, com 50 ativos, 29 parcialmente ativos e um total de 147 que tinha perdido suas características originais. Souza (2009) chegou a quantidades sensivelmente diferentes, com 54 faxinais ativos, 50 parcialmente ativos e 112 com a área do criadouro comunitário totalmente fechada. $\mathrm{O}$ autor identificou também 11 faxinais com livre acesso para criação de animais pequenos e grandes, mas localizados em terras de litígio, sem cerca ao redor da área comunitária.

O ponto mais delicado da discussão sobre o sistema faxinal ocorre acerca de sua manutenção ou desagregação, como parecem indicar os levantamentos realizados, apesar das diferenças nos números fornecidos. Barbosa (2007) afirma que o modelo tradicional de vida é ameaçado pela inserção de indivíduos provenientes de outras culturas e pela desestruturação interna do Sistema, com o surgimento de novas gerações com influência cada vez maior do meio urbano.
Para Tavares (2008), o camponês faxinalense enfrenta a questão do aumento demográfico de sua família, levando a um fracionamento da terra e redução da área disponível para produção agrícola. Para o autor, uma das formas encontradas foi a integração com empresas de fumo, que possibilita a geração de renda em área reduzida. Dos 25 faxinais visitados por Tavares, apenas um não produzia fumo.

A busca por rendimentos superiores àqueles obtidos com as atividades tradicionais, com a implantação de culturas comerciais como o fumo, é considerada uma das principais ameaça à manutenção dos sistemas faxinais. Além do fumo, Souza (2009) acrescenta as monoculturas de pinus, soja e milho e Tavares (2008) a de trigo. Almeida e Souza (2009, p. 6) reforçam a influência negativa de uma monocultura com objetivos apenas comerciais, ao enfatizar a oposição que existe entre o sistema faxinal de organização e a economia capitalista:

O valor de uso dos bens pelos faxinalenses e sua forma de produção familiar contrapõem-se ao valor de troca e aos circuitos de mercado que caracterizam uma economia mercantil e "privatista", que nega a esfera pública e as atividades econômicas baseadas no trabalho familiar.

Barbosa (2007) e Floriani et al. (2009) reforçam a ideia de incompatibilidade entre as exigências do sistema capitalista e o modo de vida tradicional dos faxinais. Este último consta de uma área comunitária, com preservação ambiental e dos valores comunitários e uma área cultivada, tradicionalmente a partir de culturas usadas para consumo próprio e comercialização apenas do excedente. Para Bertussi (2009), esse conflito explica-se pela forma de uso da terra: os povos de faxinais valorizam o uso coletivo no criadouro comunitário, 
enquanto a agricultura moderna incentiva o uso individual da terra.

A revisão da literatura destacou vários fatores considerados como responsáveis pelo declínio do sistema faxinalense, com enfoque maior no crescimento de monoculturas comerciais, incompatíveis com o modo de vida tradicional dos moradores de faxinais, além da presença de indivíduos externos ao sistema e da influência das novas gerações. Assim, a hipótese da pesquisa é que esses três fatores representam as principais ameaças para o futuro desse modo de vida. Baseado nessa, o objetivo da pesquisa foi de verificar o papel do agronegócio, da presença de "estrangeiros" ao faxinal e das mudanças culturais nas novas gerações sobre a manutenção das tradições do faxinal Taquari dos Ribeiros.

Este faxinal localiza-se no município de Rio Azul, no Sul do Paraná. Possui um criadouro comunitário de 234 ha, totalmente cercado. Neste criadouro encontram-se floresta de Araucária, animais soltos, as casas dos faxinalenses, uma igreja, mercearia, escola, posto de saúde e outros locais de vivência comunitária dos moradores (NEIVERTH e LÖWEN SAHR, 2009).

Num segundo momento foi julgado importante definir o que são os faxinais e em que consiste o modo de vida tradicional dessas comunidades. Em seguida é analisado o impacto dos principais tipos de ameaças descritos na literatura sobre a manutenção das tradições no faxinal Taquari dos Ribeiros. Finalmente são apresentadas as considerações finais da pesquisa.

\section{MODO DE VIDA TRADICIONAL DOS SISTEMAS FAXINALENSES}

Antes de identificar as dificuldades encontradas no faxinal Taquari dos Ribeiros é importante definir, a partir de uma revisão da literatura, o que se entende por faxinal e quais são as tradições que caracterizam esses sistemas.

Como exemplo da cultura tradicional de um faxinal é possível citar o exemplo de Tavares (2008) sobre o faxinal Salso, no Paraná, identificado como um faxinal que mantinha as tradições de uso da terra. Neste faxinal praticava-se a criação de animais soltos na área do criadouro e uma agricultura tradicional na terra de plantar. Esta não usava agrotóxicos, poucos insumos químicos e permitia a produção de milho, feijão, mandioca, aveia e batata-inglesa, culturas destinadas essencialmente à subsistência da família e venda apenas do excedente. Para o autor, a mandioca e o milho eram utilizados principalmente para complementar a dieta alimentar dos animais criados à solta, em particular os suínos, no período da entressafra das frutas silvestres como guabiroba, jabuticaba e pinhão. No criadouro comum podia ser encontrada também a extração da erva-mate em mutirão, ou puxirão, usada essencialmente para consumo próprio.

Para Tavares (2008), a convivência entre os habitantes do faxinal e a integração com o meio ambiente facilitam a preservação do modo de vida tradicional e da biodiversidade existente nos faxinais. Algumas das características específicas dos camponeses faxinalenses ressaltadas pelo autor são:

- Associação pecuária, agricultura e extrativismo;

- Partilha de parte das terras, em uma área definida como criadouro;

- Criação, de forma coletiva, de animais de pequeno e grande porte, soltos e misturados;

- Prática de uma agricultura de subsistência com instrumentos tradicionais;

- Partilha de sementes, criações e produtos através de trocas;

- Prática de cultura de extrativismo (erva-mate, madeira e pinhão);

- Forte convivência e integração com o meio ambiente; 
- Preservação e respeito das tradições, costumes e cultura (festas, danças e rezas).

Para Barbosa (2007), a religiosidade é um aspecto muito relevante da cultura faxinalense e que facilita a coesão social. A fim de reverenciar o sagrado, os faxinalenses elaboram festividades que, quando destinadas a um santo específico, podem ser realizadas nas casas dos habitantes. Essa prática permite o fortalecimento dos laços de amizade e de confiança entre moradores.

$\mathrm{O}$ uso dos recursos naturais nos faxinais é baseado no trabalho familiar e no uso comum da terra, o que contrasta com a posição do agronegócio capitalista, ligado às grandes plantações e aos empreendimentos industriais, cuja produção circula no mercado de commodities (SHIRAISHI NETO, 2009). Para o autor, os agentes capitalistas não reconhecem que os faxinais tradicionais possuem leis de uso e de produção de alimentos diferentes das que regem o mercado de commodities.

Tavares (2008) afirma que a introdução de mudanças nas técnicas de produção altera o processo, a relação e o significado do trabalho para o camponês faxinalense, não só com a terra, mas em todas as extensões de sua vida, entre elas a relação com os outros membros da comunidade.

Em faxinais que tinham perdido suas áreas comunitárias, Souza (2009) constatou mudanças nas relações sociais e ambientais da comunidade. $\mathrm{O}$ autor relacionou essas mudanças à aparição de novas práticas tecnológicas, como o cultivo do fumo, concentradas na especialização da mão de obra e no uso essencialmente da mão-de-obra familiar, sem recorrer à ajuda dos outros membros da comunidade. Para o autor, a focalização na família enfraquece os laços de solidariedade comunitária e facilita o fechamento das áreas de uso comum.

Souza (2009) afirma que mesmo quando uma maioria mostra-se a favor da permanência do criadouro comunitário, o direito individual dos proprietários que desejam cercar suas áreas prevalece. Para Bertussi (2009), essa situação comprova que o território de um faxinal só se mantém quando existe um consenso entre os proprietários, consenso que depende de arranjos sociais que combinem e permitam o uso comum de recursos e apropriação privada da terra.

Com a renda obtida pela fumicultura, a criação de animais soltos ou a produção para consumo próprio não são mais necessários, uma vez que não há terra e tempo para isso. Entretanto, Souza (2009) afirma que a criação de animais grandes, como vacas e cavalos, é ainda necessária para o preparo da terra e o abastecimento de carne e leite. Nos casos em que existe a possibilidade de criar esses animais em áreas de uso comum, como nas terras públicas (estradas e barrancos) e em terras privadas mantidas em comum, os faxinalenses conseguem conservar suas práticas tradicionais.

As pesquisas de Souza (2009) evidenciam a força da cultura faxinalense, que consegue manter-se até nos faxinais com grande penetração de culturas comerciais e desaparecimento de parte da área comunitária. O autor confirma a força dessas tradições e indica que em caso de necessidade, muitos faxinalenses trabalham fora, mas continuam residindo no faxinal. Alguns deles mudam para locais mais distantes em busca de empregos e, assim que alcançam condições financeiras melhores, retornam às suas comunidades. $\mathrm{O}$ autor afirma ainda que as subvenções governamentais, como aposentadorias e programas sociais diversos, também têm facilitado a permanência nos faxinais.

\section{METODOLOGIA}

A pesquisa baseou-se em estudo de caso, considerando a comunidade do faxinal Taquari dos Ribeiros, no município 
de Rio Azul, Paraná (Figura 2). Nas visitas aos atores do faxinal foram utilizadas entrevistas semiestruturadas. Todas as famílias do faxinal, num total de 82 , foram entrevistadas.

Figura 2 - Localização do município de Rio Azul e do faxinal Taquari dos Ribeiros

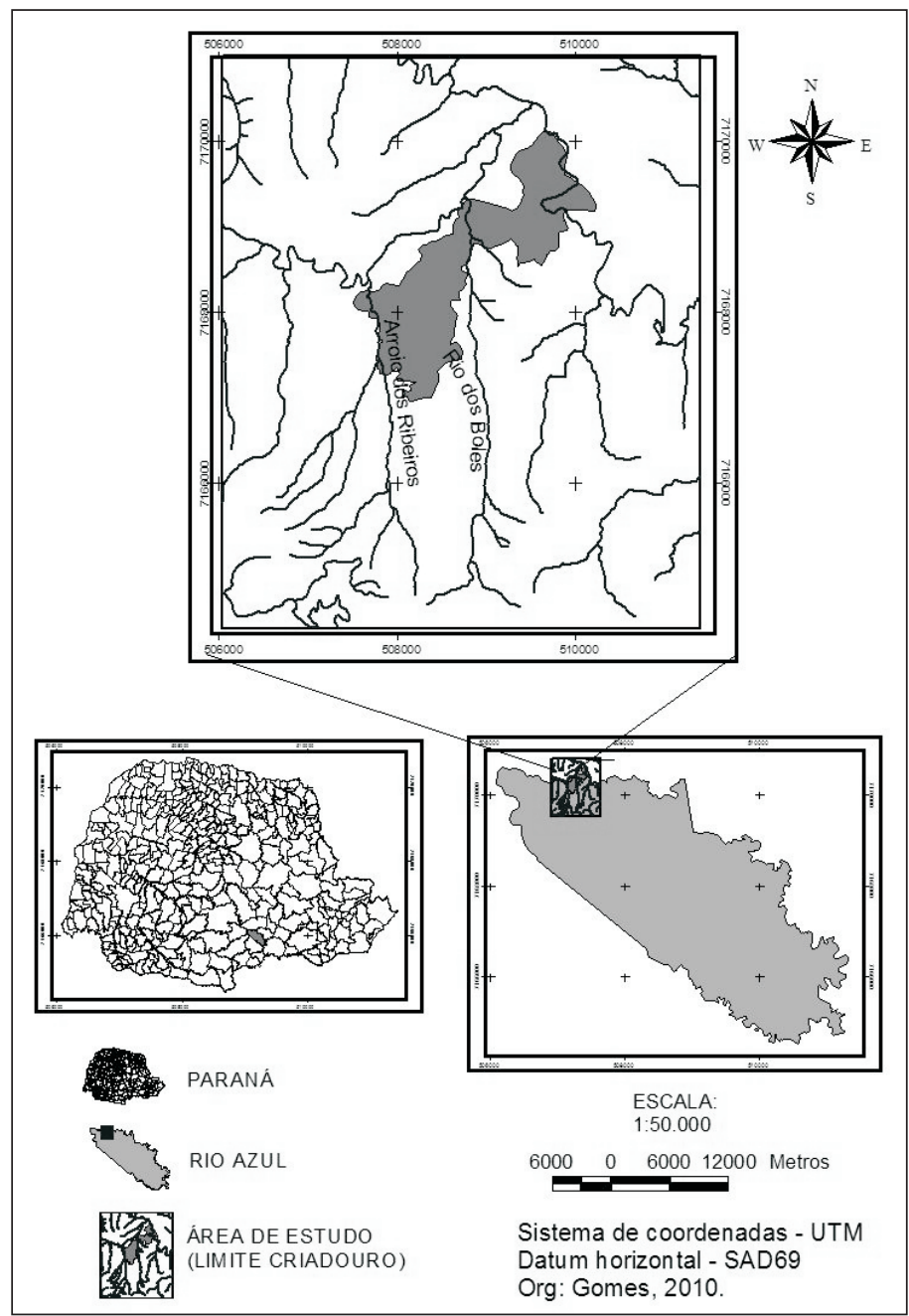

Fonte: Gomes e Ribeiro (2010)

A principal ameaça à cultura faxinalense encontra-se na manutenção do criadouro como local aberto, com livre acesso à totalidade da comunidade. Esse sistema pode ser considerado como um arranjo institucional cooperativo, em que todos concordam em deixar suas terras num sistema comunitário de livre acesso. Nesse caso, a instalação de cerca significaria o fim dessa área e, em consequência, do conceito de faxinal.
No caso do faxinal Taquari dos Ribeiros, a área comunitária continua presente e totalmente cercada, para separá-la da terra de plantar. Apesar da existência de algumas áreas cultivadas com fumo no criadouro, esse permanece relativamente intacto, o que parece indicar uma boa preservação da cultura faxinalense.

No entanto, é possível considerar a eliminação do criadouro como uma finalização do processo de desaparecimento 
da cultura faxinalense, e não de começo. Os faxinais tradicionais se caracterizam pela existência de uma cultura de solidariedade comunitária baseada em relações de reciprocidade. Essas relações se traduzem não apenas pela manutenção da área comunitária, mas também nas atividades de mutirão organizadas na comunidade, de ajuda entre moradores e nas festas comunitárias. Esses fatores, além da manutenção do criadouro e das práticas religiosas, outro aspecto levantado na literatura como relevante para a coesão da comunidade, foram avaliados para verificar o grau de ameaça à manutenção da cultura faxinalense.

A revisão da literatura permitiu identificar várias ameaças à cultura faxinalense, ameaças essas que foram avaliadas na pesquisa. O cultivo intensivo de uma cultura com fins exclusivamente comerciais foi o principal fator descrito, mas a presença de habitantes não nativos do faxinal e mudanças culturais nos jovens foram também apontadas como relevantes.

A partir das características culturais dos faxinais e dos fatores de ameaça foi possível definir a Quadro 1, que serviu de base para a análise.

Quadro 1 - Fatores utilizados na análise das principais ameaças à cultura tradicional no faxinal Taquari dos Ribeiros

\begin{tabular}{|c|c|c|c|c|}
\hline & & \multicolumn{3}{|c|}{ Fatores culturais } \\
\hline & & Área comunitária & Solidariedade & Religiosidade \\
\hline \multirow{3}{*}{ 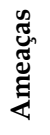 } & Agronegócio mercantil & & & \\
\hline & Habitantes de fora & & & \\
\hline & Mudanças dos jovens & & & \\
\hline
\end{tabular}

A análise do faxinal Taquari dos Ribeiros avalia a influência das diferentes ameaças descritas na Quadro 1 sobre os fatores culturais. A importância da área comunitária foi avaliada a partir da presença de criação animal. Foi considerado que o criadouro era mais importante para os moradores com esse tipo de atividade.

Além da criação animal, a presença de culturas tradicionais para consumo próprio e de atividades extrativas, principalmente de erva mate, foi verificada, por considerar essas atividades como tradicionais do modo de vida faxinalense.

Os aspectos de solidariedades foram identificados a partir da participação em atividades coletivas, como mutirão, associação e plantio em parceria. Foi também avaliado o empréstimo de implementos e de dinheiro entre os moradores da comunidade.

A religiosidade foi avaliada a partir da participação nos ofícios religiosos e em festas do Santo em casa.
A avaliação dos resultados foi feita a partir de análises de correlação e testes $t$ de Student para comparação das médias de amostras independentes. Esse teste permitiu verificar a relevância das diferenças observadas nos resultados. Pela nomenclatura adotada na pesquisa, diferenças muito significativas entre as médias foram aquelas com valor de probabilidade (p) inferior ou igual ao nível de significância $(\alpha)$ de 0,05 . Valores de p entre 0,1 e 0,05 indicaram diferenças significativas. Um valor de probabilidade superior a 0,1 significa a impossibilidade de concluir pela diferença da média entre os grupos avaliados para o fator considerado.

\section{FATORES QUE AMEAÇAM A CULTURA FAXINALENSE}

Nesse Item são abordados os resultados da pesquisa, com a apresentação das três ameaças descritas na Tabela 1, a presença 
de um sistema de produção voltado para o agronegócio capitalista, a existência de habitantes originários de fora do faxinal e as mudanças culturais nos jovens.

\subsection{Impacto das culturas destinadas exclusivamente à comercialização}

O fumo participava da renda familiar de 56 moradores do faxinal, ou $70 \%$ do total. Desse total, 52 afirmaram que a cultura representava sua renda principal (Figura 3). A produção animal alcançou apenas a terceira posição, interessando apenas $22 \%$ dos faxinalenses e nunca apareceu como fonte de renda principal. A comercialização de erva mate já foi muito importante para as comunidades de faxinais, sendo, conforme informado por Tavares (2008), a principal fonte de renda. Na época da pesquisa, essa atividade era apenas marginal no faxinal Taquari dos Ribeiros.

De acordo com a literatura, o potencial de renda com o cultivo de fumo, atividade principal do faxinal Taquari dos Ribeiros, deveria pressionar os moradores a utilizar suas áreas no criadouro para produção dessa cultura. A Figura 4 indica que 21 produtores de fumo possuíam mais de $20 \%$ de suas terras no criadouro e poderiam ser interessados em aumentar suas produções

Figura 3 - Fontes de renda dos membros da comunidade do faxinal Taquari dos Ribeiros, PR, em 2009

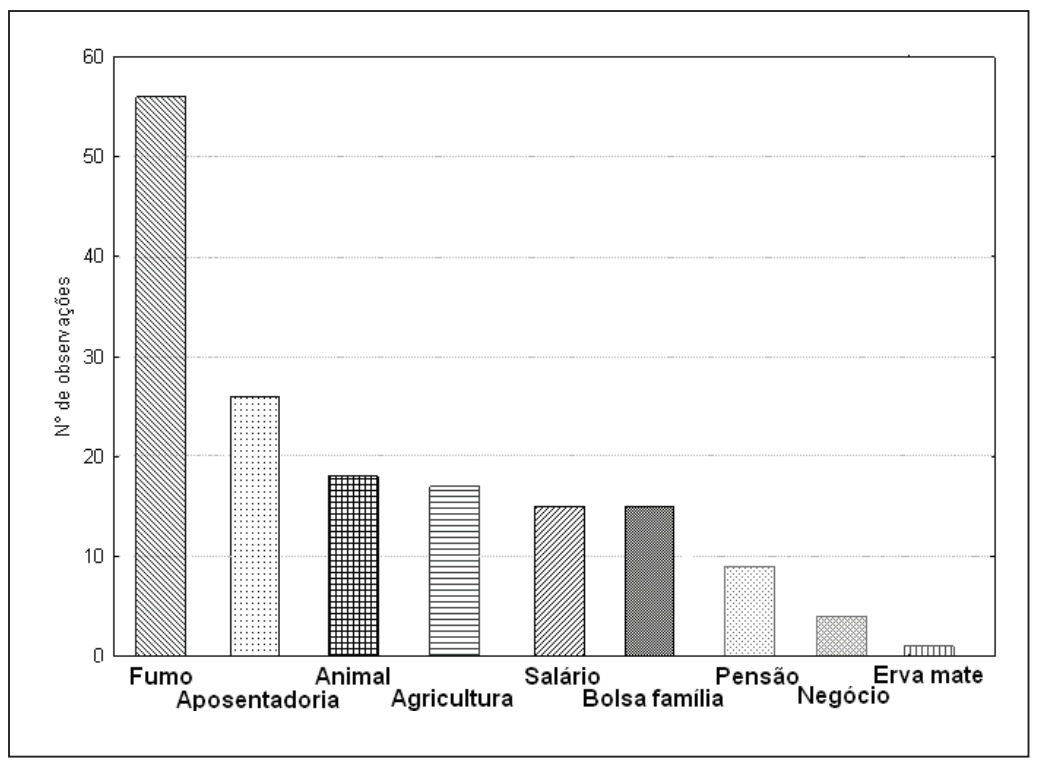

nesse espaço. No entanto, no momento das entrevistas, apenas dois produtores já tinham iniciado esse processo.

Floriani et al. (2009) afirmam que a configuração do solo pode ajudar a preservar as terras de plantar do faxinal Taquari e limitar a expansão do fumo. As terras brancas, adaptadas ao cultivo do fumo, estão localizadas nas terras de plantar, enquanto as terras onde o cultivo do fumo é mais difícil estão localizadas nas áreas do criadouro. Mesmo assim, algumas áreas do criadouro possibilitariam o plantio de fumo com correção adequada do solo.

A pesquisa no faxinal Taquaridos Ribeiros permitiu identificar 7 fontes de renda: atividade salarial, produção de fumo, produções agrícolas outras além do fumo, produção de animais e seus derivados, negócios particulares, aposentadoria e bolsas do Governo, 
Figura 4 - Áreas dos produtores de fumo do faxinal Taquari dos Ribeiros, PR, nas terras de plantar e no criadouro, em 2009

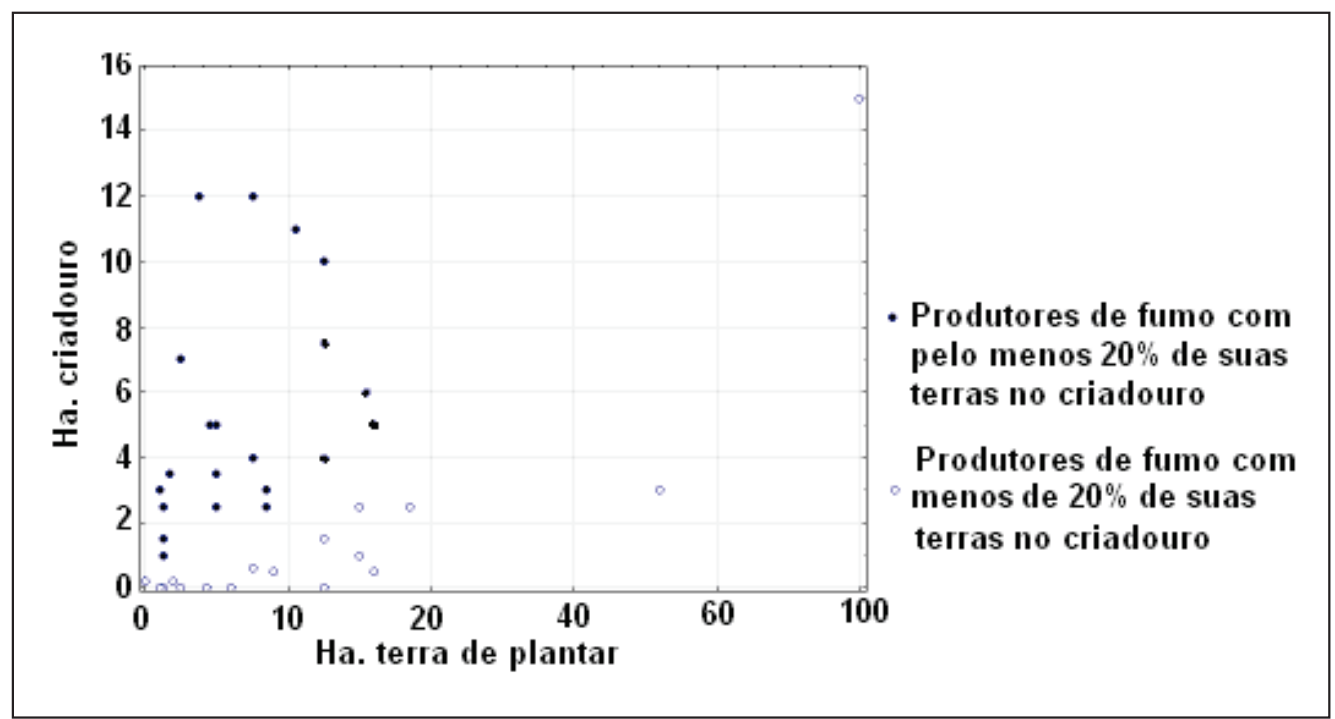

principalmente a bolsa família. A comercialização de erva mate participou da renda familiar de apenas dois entrevistados, $\mathrm{e}$ foi considerada como de influência muito limitada na renda familiar mensal dos faxinalenses.

A análise das fontes de renda encontradas no faxinal Taquari dos Ribeiros sobre a renda mensal familiar, apresentada na Tabela 1, evidenciou resultados bastante diferentes daqueles esperados. A realização de atividades assalariadas e o plantio de fumo não permitiam a obtenção de uma renda significativamente maior. Em compensação, a comercialização de produtos animais, atividade tradicional dos faxinais, mostrou ter um impacto bem maior, com diferença muito significativa entre aqueles que comercializavam esse tipo de produtos e os outros moradores.

Nenhum entrevistado declarou a produção animal como única fonte de renda, uma vez que sempre era complementada por outra fonte de renda, o que explica as rendas familiares mensais maiores.

Tabela 1 - Influencia das diferentes fontes de renda encontradas no faxinal Taquari dos Ribeiros, PR, sobre a renda familiar mensal das famílias, em 2009

\begin{tabular}{|c|c|c|c|c|c|}
\hline \multirow{2}{*}{ Fontes de renda } & \multicolumn{2}{|c|}{ Nível de renda médio* } & \multicolumn{2}{|c|}{$\mathbf{N}^{\circ}$ de pessoas entrevistadas } & \multirow[b]{2}{*}{$\mathbf{p}$} \\
\hline & $\begin{array}{l}\text { Sem a fonte } \\
\text { de renda }\end{array}$ & $\begin{array}{l}\text { Com a fonte } \\
\text { de renda }\end{array}$ & $\begin{array}{l}\text { Sem a fonte } \\
\text { de renda }\end{array}$ & $\begin{array}{l}\text { Com a fonte } \\
\text { de renda }\end{array}$ & \\
\hline Salário & 2,03 & 1,79 & 61 & 14 & 0,23 \\
\hline Fumo & 1,86 & 2,04 & 21 & 54 & 0,31 \\
\hline Produção agrícola & 1,91 & 2,24 & 58 & 17 & 0,09 \\
\hline Produção animal & 1,88 & 2,33 & 57 & 18 & 0,01 \\
\hline Negócio & 1,96 & 2,50 & 71 & 4 & 0,13 \\
\hline Aposentadoria & 1,98 & 2,00 & 51 & 24 & 0,91 \\
\hline Bolsa Governo & 2,05 & 1,73 & 60 & 15 & 0,11 \\
\hline
\end{tabular}

* Nível de renda: 1: < 1 Salário Mínimo (SM); 2: 1 a 3 SM; 3: 3-5 SM; 4: > 5 SM.P: valor de probabilidade de igualdade da média. 
Produtores com produções agrícolas outras além do fumo apresentavam também renda familiar mensal superior aos outros moradores do faxinal, com diferença considerada significativa no teste $t$. Entre os produtores com produção agrícola outra que o fumo, 9 declararam comercializar milho, 6 feijão,um soja e um tomate. A comercialização de milho, soja e tomate não se diferencia muito daquela do fumo e evidencia a influência do agronegócio capitalista sobre a vida dos moradores do faxinal Taquari dos Ribeiros. A comercialização de feijão é a única que mantém as tradições do faxinal, no entanto ela representa poucos produtores.

Como para a comercialização animal, a venda de produtos agrícolas outros que o fumo é sempre complementada por outra atividade, principalmente a fumicultura. Nesse caso, essas atividades agrícolas apresentam papel de complementação de renda, o que explica, como para a produção animal, os maiores níveis de renda familiar.

Apesar de ser a segunda fonte de renda mais frequente, a aposentadoria não permite uma renda familiar mensal significativamente maior para seus beneficiários. A grande quantidade de aposentados reflete um envelhecimento do faxinal, similar aquele encontrado nos assentamentos do Mato Grosso do Sul por Vilpoux e Oliveira (2011), o que não é desejável para a manutenção do faxinal. Em compensação, o fumo oferece uma oportunidade de renda para um grande número de faxinalenses, o que pode facilitar a permanência dos moradores mais jovens.

Os resultados da Tabela 1 permitem estabelecer a importância dos produtos oriundos de cultivos intensivos destinados ao mercado, como enfatizado na literatura, a exemplo do fumo, que permite renda para dois terços dos moradores do faxinal do Taquari dos Ribeiros e outros produtos, como milho e soja no mercado de commodities, que permitem complementar a renda familiar.
Além de comprovar a importância para o faxinal do agronegócio capitalista ligado às grandes empresas, é necessário verificar o impacto sobre a manutenção da cultura local.

A análise estatística não mostrou diferença significativa na produção animal e de erva mate entre os produtores de fumo e os outros moradores do faxinal. Esse resultado indica que a produção de fumo não interfere no uso do criadouro, com criação animal e extração de erva mate.

A integração do produtor no agronegócio capitalista poderia também desestruturar as relações entre os habitantes do faxinal, como relatado por Tavares (2008) e Shiraishi Neto (2009). A Tabela 2 analisa a participação dos produtores, em função da produção ou não de fumo, nas atividades cooperativas do faxinal Taquari dos Ribeiros.

A análise não mostrou diferença significativa no plantio em parceria, na participação em mutirões e na associação comunitária. O resultado médio para plantio em parceria e participação da associação comunitária é mais próximo de 0 , valor utilizado para indicar a ausência de parceria e de envolvimento em associação. Esse resultado indica que a maioria dos moradores planta sozinho e não participa de associação, sem interferência do tipo de cultivo.

Os valores utilizados na análise da participação em mutirões foram de 0 para aqueles que nunca participam, 1 para aqueles que já participaram de apenas um tipo de mutirão (renovação da cerca no entorno do criadouro, ajuda a pessoas doentes da comunidade, limpeza das áreas comuns, construção de poços, instalação de água e telefone) e 2 para os que já participaram de vários tipos de mutirões. O resultado médio para participação de mutirões foi de 1,0 que significa que os moradores participam pouco desse tipo de atividade, com ou sem cultivo de fumo. 
Tabela 5 - Influência do plantio de fumo sobre atividades cooperativas, entre os moradores do faxinal Taquari dos Ribeiros, PR, em 2009

\begin{tabular}{|c|c|c|c|c|c|}
\hline \multirow[b]{2}{*}{ Variáveis avaliadas } & \multicolumn{2}{|c|}{ Plantio de fumo } & \multicolumn{2}{|c|}{$N^{\circ}$ de pessoas entrevistadas } & \multirow[b]{2}{*}{$\mathbf{p}$} \\
\hline & Sim & Não & $\begin{array}{l}\text { Plantam } \\
\text { fumo }\end{array}$ & $\begin{array}{l}\text { Não plantam } \\
\text { fumo }\end{array}$ & \\
\hline Planta em parceria & 0,37 & 0,26 & 54 & 19 & 0,40 \\
\hline Participa de mutirões & 1,00 & 1,17 & 56 & 23 & 0,54 \\
\hline Divide implementos & 0,78 & 0,44 & 54 & 18 & 0,01 \\
\hline Confia para emprestar dinheiro & 1,74 & 1,33 & 50 & 18 & 0,15 \\
\hline Participa da associação comunitária & 0,47 & 0,33 & 55 & 21 & 0,28 \\
\hline
\end{tabular}

Legenda: Para as variáveis "Planta em parceria", "Divide implementos" e "Participa da associação comunitária": $0=$ não; $1=$ sim "Participa de mutirões": 0 = não; 1 = participou num tipo (cultura, cerca, poço, limpeza); 2 = participou em mais de 1 tipo - "Confia para emprestar dinheiro": 0 = Ninguém; 1 = apenas membros da família; 2 = parte dos moradores do faxinal; 3 = todos os moradores do faxinal. P: valor de probabilidade de igualdade da média.

Em compensação, os resultados da Tabela 2 indicam que os produtores de fumo dividem mais implementos com os outros moradores do faxinal. Apesar de não significativos, provavelmente em função da pequena quantidade de moradores que não plantava fumo, os resultados indicam também uma tendência dos produtores de fumo em confiar mais nos outros moradores do faxinal, fora do círculo familiar, para emprestar dinheiro. Esses resultados são contrários àqueles que eram previstos a partir da revisão da literatura e parecem indicar um maior espírito de solidariedade entre os produtores de fumo. Nesse caso, não é possível afirmar que o agronegócio capitalista apresenta papel desestruturador sobre as relações entre os membros da comunidade.

A Figura 5 indica que todos os produtores de fumo começaram o cultivo a mais de 10 anos, a maioria desde os anos oitenta. Nesse caso, em função dos resultados, é possível concluir que a cultura do fumo já está bem implantada no faxinal Taquari dos Ribeiros e conseguiu se adaptar as tradições locais.

Figura 3 - Ano do inicio de cultivo de fumo, para os produtores entrevistados no faxinal Taquari dos Ribeiros, PR, em 2009

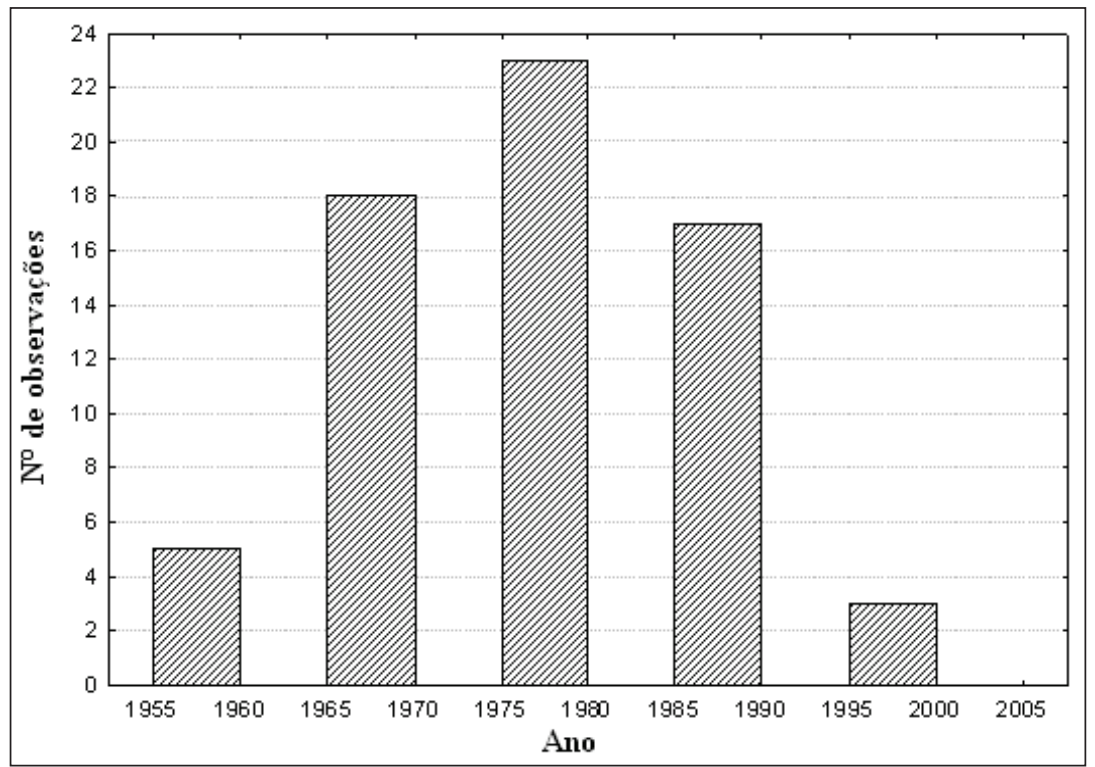


Como último elemento avaliado, a religiosidade não indicou grande diferença de comportamento entre produtores de fumo e outros moradores. A frequência de participação em missas foi similar entre todos os entrevistados, com a média de uma missa a cada 9 ou 10 dias.

A tradição das festas do Santo em casa está desaparecendo do faxinal e foi pouco praticada pelos mais jovens. Entre todos os entrevistados, apenas $10 \%$ declararam ainda organizar ou participar desse tipo de festividades e $20 \%$ informaram que antigamente participavam, mas que nos últimos anos as festas acabaram.

Em relação ao impacto do fumo, principal atividade do agronegócio capitalista encontrada no faxinal Taquari dos Ribeiros, não foi identificada interferência sobre manutenção do criadouro e as práticas de solidariedade típicas dos faxinais. Pelo contrário, os resultados indicam maior tendência de emprestar implementos entre produtores de fumo.

\subsection{Influência dos moradores nascidos fora do faxinal}

É de se esperar que moradores que nasceram ou que vivem há muito tempo no faxinal estejam mais ligados com a cultura local e que se interessem mais em manter as tradições faxinalenses, principalmente em relação à preservação da área do criadouro. Para $40 \%$ das famílias, o casal nasceu no local e em $35 \%$ dos casos, pelo menos um dos dois era originário do faxinal, o que significa que $57 \%$ dos moradores nasceram na comunidade.

Entre aqueles que nasceram fora do faxinal, dois terços já moravam no local há mais de 20 anos (Figura 6). Apenas 6\% dos habitantes do faxinal residiam no lugar há menos de 5 anos, metade deles casados com moradores nascidos no faxinal.
A avaliação da origem dos moradores do faxinal indicou grande proporção de habitantes originários da comunidade, o que reforça a ligação com o local e suas tradições e pode limitar as veleidades de mudança dos habitantes. A preservação da cultura faxinalense passa pela participação de todos os moradores, com uma vontade comum de conservação. Essa necessidade aparecia muito claramente para os habitantes da comunidade, que percebiam que a desistência de alguns, com o fechamento da área comunitária, prejudicava a todos e ameaçava o futuro dessa área.

A comparação de média com o teste $t$ de Student permitiu estabelecer ausência de impacto da origem dos moradores, que não interferiu no tipo de atividade praticada. A proporção de produtores de fumo, de animais e de erva mate foi a mesma nas famílias com os dois membros de fora, apena um de fora ou os dois do faxinal. A renda familiar mensal também foi similar.

Os habitantes do faxinal que não nasceram na comunidade participavam tanto quanto os outros das atividades Comunitárias e religiosas, o que vai ao encontro da 
afirmação de Barbosa (2007). No entanto, o autor se referia essencialmente à influência de pessoas oriundas da cidade, que utilizavam o faxinal apenas como chácara de fim de semana, ou de produtores ligados ao agronegócio capitalista, que adquiriam a terra apenas com finalidade comercial. O faxinal Taquari dos Ribeiros é bastante isolado dos grandes centros urbanos, o que limita a influência de chacareiros. Em paralelo, a atividade do agronegócio capitalista se limita essencialmente à produção de fumo, com muitas áreas acidentadas que limitam o desenvolvimento de milho e soja. Ao contrário dessas duas culturas, que possuem economia de escala, o fumo exige grande quantidade de mão de obra, essencialmente familiar, o que limita a área cultivada e pode ter contribuído a preservar a estrutura típica do faxinal Taquari dos Ribeiros.

\subsection{Mudanças culturais nos jovens moradores do faxinal}

A análise da influência do agronegócio mercantil e dos moradores nascidos fora dos faxinais não indicou nenhuma ameaça direta a sobrevivência do estilo de vida faxinalense.

Apesar da influência dos moradores mais jovens na vida do faxinal Taquari dos Ribeiros ser o último fator avaliado, é considerado com grande potencial de interferência na tradição faxinalense.

A análise indicou diferença muito significativa na idade dos produtores de fumo, com média de 43,7 anos, contra 63,0 para os moradores que não trabalhavam com a cultura. Em paralelo, a idade não interferiu nas outras produções, como criação animal e extração de erva mate. Esses resultados indicam que se os jovens adotam com mais facilidades culturas mais comerciais, ligadas a grandes empresas, eles não abandonam as outras atividades tradicionais do faxinal.

Tavares (2008) relatou que o fracionamento das áreas, ligado à divisão da terra entre membros da mesma família, obriga os faxinalenses a recorrer a culturas mais comerciais para sustentar suas famílias. Nesse caso, seria de se esperar áreas menores entre moradores mais novos em relação aos mais velhos, que herdaram ou compraram suas terras há muito mais tempo. No entanto, os resultados não mostraram nenhuma correlação $\left(R^{2}<0,05\right)$, entre a área da terra de plantar ou do criadouro e a idade do proprietário. Uma explicação possível para a manutenção da área disponível por família, apesar do potencial de fragmentação ligado aos fenômenos de herança, é o êxodo rural dos mais jovens, que deixam o campo para morar na cidade. Esse fenômeno leva a uma maior permanência de pessoas idosas na comunidade, o que explica a importância da aposentadoria na renda familiar.

$\mathrm{Na}$ época da pesquisa existia uma cooperação entre os habitantes do faxinal Taquari dos Ribeiros. Em 2009, dois terços dos membros da comunidade declararam participar de mutirões, o que denota envolvimento na vida coletiva do faxinal, mesmo se, na maioria dos casos, os moradores participaram de apenas um tipo de mutirão. Entre as atividades objeto dos mutirões, a mais citada foi a renovação da cerca no entorno do criadouro, seguida da ajuda a pessoas doentes da comunidade, limpeza das áreas comuns, construção de poços e instalação de água e telefone.

O perfil etário e educacional entre os membros da comunidade que participavam de mutirões foi significativamente diferente, com envolvimento menor dos mais jovens. A análise revelou 36 moradores que não participavam de mutirão, com idade média de 45 anos, contra 33 que costumavam participar, com idade média de 53 anos. 
Entre as demais atividades comunitárias, como plantio em parceria e divisão de ferramentas, não foi identificada nenhuma interferência da idade. No entanto, as informações coletadas indicavam uma diminuição da cooperação entre todos os moradores. Um terço declarou não dividir seus implementos com ninguém e dois terços plantavam sozinhos. Metade dos moradores informou não participar de associação e $8 \%$ participavam de uma organização não ligada ao faxinal. Esses dados podem significar um desinteresse relativamente elevado pela vida na comunidade, desinteresse que não se limita apenas aos jovens.

Em relação aos aspectos de religiosidade, a idade não mostrou interferência na ida à igreja. Os jovens apenas declararam nunca ter participado das festas de Santo em casa, o que é compreensível, pois os moradores mais velhos que participavam afirmaram que estas festas acabaram há vários anos. No caso dos homens, a idade média dos faxinalenses que ainda participavam das festas do Santo em casa foi de 59 anos, enquanto foi de 46 para os que não participavam, sendo a diferença muito significativa. No caso das mulheres, a diferença de idade entre os dois grupos não foi significativa.

\section{CONSIDERAÇÕES FINAIS}

A análise do faxinal Taquari dos Ribeiros demonstrou a grande complexidade dos fatores que podem ser responsáveis pela evolução cultural em um faxinal. Esses resultados são resumidos na Tabela 3 .

Tabela 3 - Principais ameaças à cultura tradicional no faxinal Taquari dos Ribeiros, PR

\begin{tabular}{|c|c|c|}
\hline Aspectosavaliados & Principais ameaças & Efeitos das ameaças \\
\hline Área comunitária & $\begin{array}{l}\text { Agronegócio } \\
\text { Origem moradores } \\
\text { Idade moradores }\end{array}$ & Sem efeito \\
\hline Solidariedade & $\begin{array}{l}\text { Agronegócio } \\
\text { Origem moradores } \\
\text { Idade moradores }\end{array}$ & $\begin{array}{l}\text { Mais troca de implementos nos produtores de fumo } \\
\text { Sem efeito } \\
\text { Mais participação em mutirões nos mais velhos }\end{array}$ \\
\hline Religiosidade & $\begin{array}{l}\text { Agronegócio } \\
\text { Origem moradores } \\
\text { Idade moradores }\end{array}$ & $\begin{array}{c}\text { Sem efeito } \\
\text { Sem efeito } \\
\text { Pouco efeito. Homens jovens participam menos das } \\
\text { festas do Santo em casa }\end{array}$ \\
\hline
\end{tabular}

O desenvolvimento de um agronegócio ligado a grandes empresas, como o fumo, cultura mais encontrada no faxinal, parece favorecer mudanças nas produções agrícolas tradicionais dos faxinalenses, normalmente concentradas no consumo próprio. Não entanto, os resultados da pesquisa não confirmaram que essa evolução leva à desestruturação das regras internas à comunidade, ao contrário do afirmado por alguns autores.
Os resultados obtidos no faxinal Taquari dos Ribeiros identificaram cooperação maior entre os produtores de fumo e uma convivência de muitos anos dessa atividade com a vida faxinalense. Na comunidade estudada, o cultivo de fumo não parece ter influenciado a importância da produção animal no criadouro.

Pelo contrário, o fumo possui um papel relevante na geração de renda para a maioria 
dos moradores, papel que permite a manutenção dos faxinalenses e pode favorecer a sobrevivência da comunidade, facilitando a permanência dos jovens.

Outro fator considerado como relevante, a presença de moradores nascidos fora do faxinal não interferiu na cultura da comunidade. Os moradores externos que se instalaram no faxinal Taquari dos Ribeiros vieram para ficar e adotaram os modos de vida local.

Apesar da participação em mutirões, principalmente na população mais velha, e da existência de troca de implementos nos produtores de fumo, foi possível perceber uma solidariedade reduzida entre os membros da comunidade. Poucos produtores participam de uma associação, mesmo da associação comunitária, e as festas do Santo em casa, antes consideradas muito importantes para a coesão da comunidade, desapareceram. Esses aspectos indicam degradação da coesão social dentre da comunidade, situação já iniciada há muitos anos. Essa degradação representa a principal ameaça identificada para o faxinal.

Apesar do desaparecimento das festas de Santo em casa, a vida religiosa continua com papel preponderante na vida da comunidade. Foi constatada uma grande homogeneidade entre a população do faxinal Taquari dos Ribeiros, com 95\% dos entrevistados se declarando católicos, todos afirmando participar das missas.

A religião é um elemento importante de agregação na comunidade e envolve a quase totalidade dos habitantes. É um elemento que poderia servir em aproximar os moradores e reforçar os vínculos entre eles, com o objetivo comum de preservação da comunidade.

\section{REFERÊNCIAS}

ALMEIDA, A.W.B. de; SOUZA, R.M. de (org.). Terras de faxinais. Manaus, Edições da Universidade do Estado do Amazonas - UEA, 2009. $184 \mathrm{p}$.

ARTICULAÇÃO PUXIRÃO DOS POVOS FAXINALENSES - APF. Carta do III Encontro dos Povos faxinalenses. Irati, Paraná, 2009. Disponível em: <http:/ / terradedireitos.org.br/biblioteca/ carta-do-iii-encontro-dos-povos-faxinalenses/>. Acesso: Março 2011.

BARBOSA, T. A. Território e territorialidades do sistema faxinal: análise a partir da reconstrução histórica familiar na Comunidade Taquari dos Ribeiros em Rio Azul/ PR. 2007. 85 p. Trabalho de Conclusão de Curso apresentado para a obtenção de título de bacharel em Geografia na Universidade Estadual de Ponta Grossa, Área de Geociências, 2007.

BERTUSSI, M.L. faxinais: um olhar sobre a territorialidade, reciprocidade e identidade étnica. In ALMEIDA, A.W.B. de; SOUZA, R.M. de (org.). Terras de faxinais. Manaus: Edições da Universidade do Estado do Amazonas - UEA, 2009. p. $150-166$.

EGGER, A. Geoökologische Untersuchungdes Faxinal-Waldweidesystemsder Hochländer von Paraná, Südbrasilien. 2009. 169 p. Tese de Doutorado em Geografia, Universidade de Heidelberg, Faculdade de Química e Geociências, Instituto de Geografia.2009

FLORIANI, N; CARVALHO, S.M.; FLORIANI, D.; SILVA, A.A.I. Da; STRACHULSKI, J. Modelos híbridos de agricultura em um faxinal paranaense: confluência de imaginários e de saberes agrícolas, 2010. 22 p.

GOMES, I.A. e RIBEIRO, S.R.A. Espacialização etnopedológica das terras do faxinal Taquari dos Ribeiros - Pr: uma abordagem com uso das geotecnologias. Terr@Plural, Ponta Grossa, v.4, n.1, p.77-94, 2010.

LÖWEN SAHR, C. L. e CUNHA, L. A. G. O significado social e ecológico dos faxinais: reflexões acerca de uma política agrária sustentável para a região da mata com araucária no Paraná. Emancipação, v.5, n.1,p. 89-104, 2005.

NEIVERTH, N. ; LÖWEN SAHR, C. L. Terra e cultura faxinalense: reflexões em torno de políticas 
e ações governamentais na Comunidade Taquari dos Ribeiros (Rio Azul/PR). 2009, 11 p.

SHIRAISHI NETO, J. O direito dos povos dos faxinais: as interpretações e as interpretações jurídicas. In ALMEIDA, A.W.B. de; SOUZA, R.M. de (org.). Terras de faxinais. Manaus: Edições da Universidade do Estado do Amazonas - UEA, 2009. p. 17-28.

SOUZA, R.M.De. Mapeamento social dos faxinais no Paraná. In ALMEIDA, A.W.B. de; SOUZA, R.M. de (org.). Terras de faxinais. Manaus: Edições da Universidade do Estado do Amazonas - UEA, 2009. p. $29-88$.

TAVARES, L.A. Campesinato e os faxinais do Paraná: as terras de uso comum. 2008.756 p. Tese de Doutorado em Geografia Humana, Universidade de São Paulo, Faculdade de Filosofia, Letras e Ciências Humanas, Departamento de Geografia, Programa de Pós-graduação em Geografia Humana. 2008

VILPOUX, O.F.; OLIVEIRA, M. A. C. de. Agricultura familiar e desenvolvimento sustentável. In. VILPOUX, O.F. (Org.). Sustentabilidade e Agricultura Familiar. Editora CRV, Curitiba, 2011. p. 13-54

Recebido em: 17/10/11 Aceito em: 14/12/11 